\title{
To Widen the Cycle: Artists Engage the Menstrual Cycle and Reproductive Justice
}

\author{
Curated and Edited by Jen Lewis
}

In order to break the social and cultural stigma around the menstruating body, we must expand the conversation, or widen the cycle. We must begin to see all the ways that the menstrual cycle touches lives. We must acknowledge that menstruation is a human right that deserves a public dialogue, not simply the shame and silence that have been handed down from generation to generation. One way to do this is through the power of art.

In 2015 at the Society for Menstrual Cycle Research biennial conference in Boston, USA, I curated Widening the Cycle-a diverse collection of work by 36 artists from ten countries that situated menstruation within the reproductive justice framework. The aim of the exhibit was to make the invisible visible and push the boundaries of what we know about the menstrual cycle. This chapter titled "To Widen the Cycle: Artists Engage the Menstrual Cycle and Reproductive Justice" presents a selection of works and artists' statements from that historic exhibit. (For more information, visit www.wideningthecycle.com.) It builds on the Feminist and Body Art Movements that started in the 1960s. Whether directly or indirectly influenced, the artists in this collection continue a dialogue started by Judy Chicago, Carolee Schneemann, and Ana Mendieta. Their work reflects an intersectional approach to feminism, a rise in radical self-acceptance, a resurgence of the DIY spirit popularized with the Riot Grrl movement of the 1990s, and the power of social media to facilitate a revolution. The art selected for this Handbook and the wider collection from which it comes threads together global voices to raise consciousness about menstruation and reproductive justice through feminist art.

Aesthetically, the pieces that follow vary greatly, but they are united by the desire to reframe the social narrative surrounding menstruation and reclaim 
this natural process as something positive rather than negative-erasing "the curse" mentality. Perhaps the most important takeaway from "To Widen the Cycle" is recognizing that this stigmatization is about gendered blood. For example, Ingrid Goldbloom Bloch's piece "Feminine Protection" illustrates the disparity between blood spilled in violence and blood shed during the menstrual cycle. The former is widely accepted and a common staple of popular entertainment, while the latter is reviled despite its connection to life and creation. Illuminating our monthly blood inserts menstruation into the broader gender equality discussion, empowers us to neutralize stigma, normalizes our bodies, and revolutionizes the way society sees bodies that menstruate.

\section{Artist's Statement}

Danielle Boodoo-Fortuné

O green god, first mother

She who made the water,

lay your hands on me

shake the firmament

of my body,

deliver me from doubt. (Fig. 58.1)

\section{ARTisT's STATEMENT}

\section{Gabriella Boros}

In Hebrew, niddah means a menstruating woman, literally, "one who is excluded." According to Jewish law, a man is forbidden to maintain sexual relations with his wife during and after her menses, since anything she touches is impure and can cause impurity to others. In this project, the concepts betray a negativity that is inherent in the Talmudic view of women's cycles (written in $2 \mathrm{AD}$ ), as well as my ambivalence to the bodily process.

The Curses illustrates the negative physical manifestations that women may have during menstrual periods. The Curses, named after the Victorian term for menstruation, are depicted in elegant single linear fashion with a traditional female medium: embroidery. By abstracting the figures somewhat, I create a beautiful image for painful or embarrassing side effects. In addition, by styling the images on banners, I reverse the usual proud representation of a family coat of arms to a shameful or hard issue. At the bottom of the banners are bdikah cloths, used by Orthodox Jewish women to check for purity in the seven days following menses. I have painted them with abstractions rather than the light stains of menstrual blood to give these negative side effects a positive, colorful secondary focus (Fig. 58.2). 
Fig. 58.1 The Burden of Bearing. Medium: watercolor, acrylic, collage, and ink (Credit: Danielle BoodooFortunè 2013)
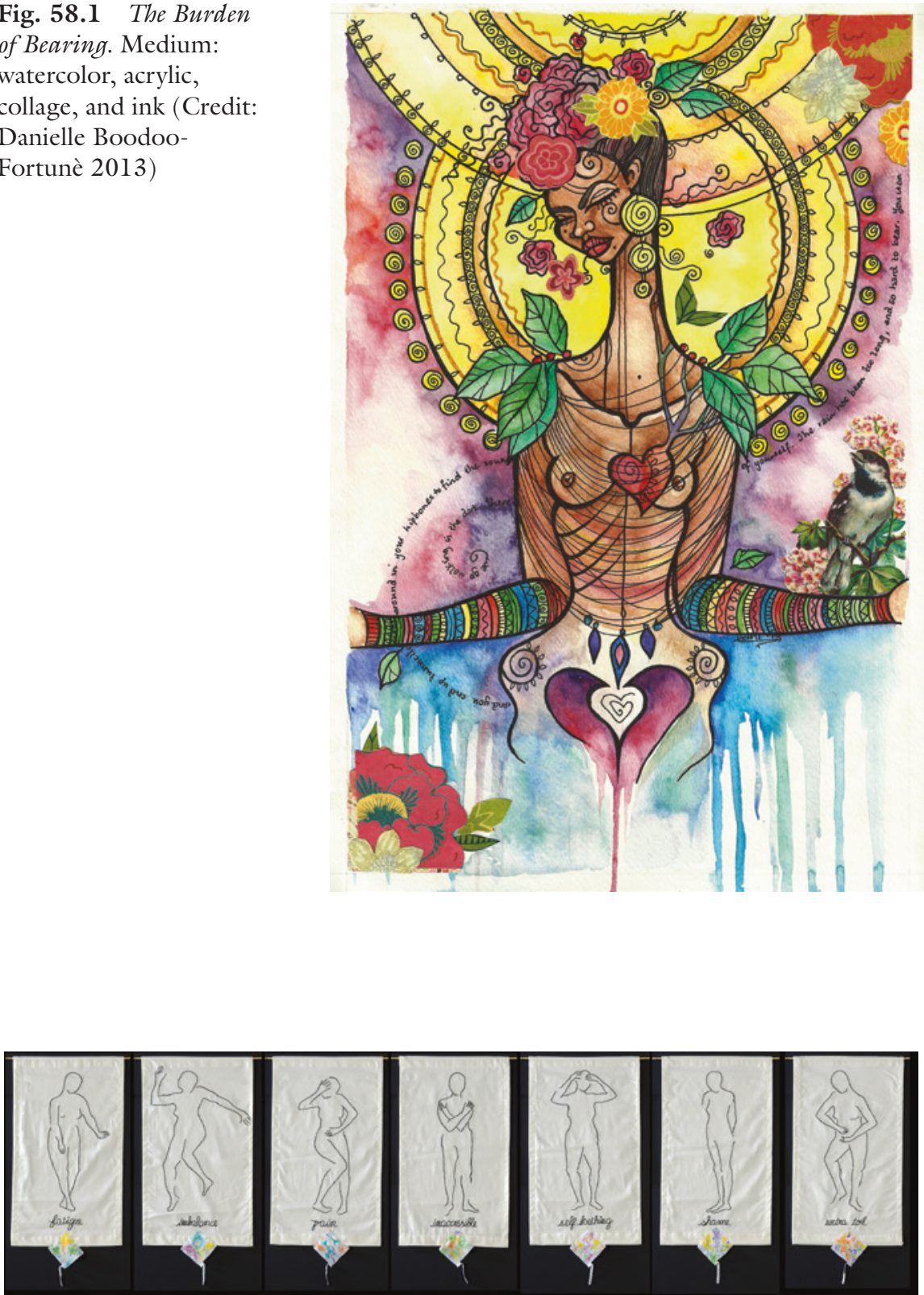

Fig. 58.2 From left to right, the text on the banners reads: fatigue, imbalance, pain, inaccessible, self loathing, shame, extra toil (Credit: Gabriella Boros 2012) 


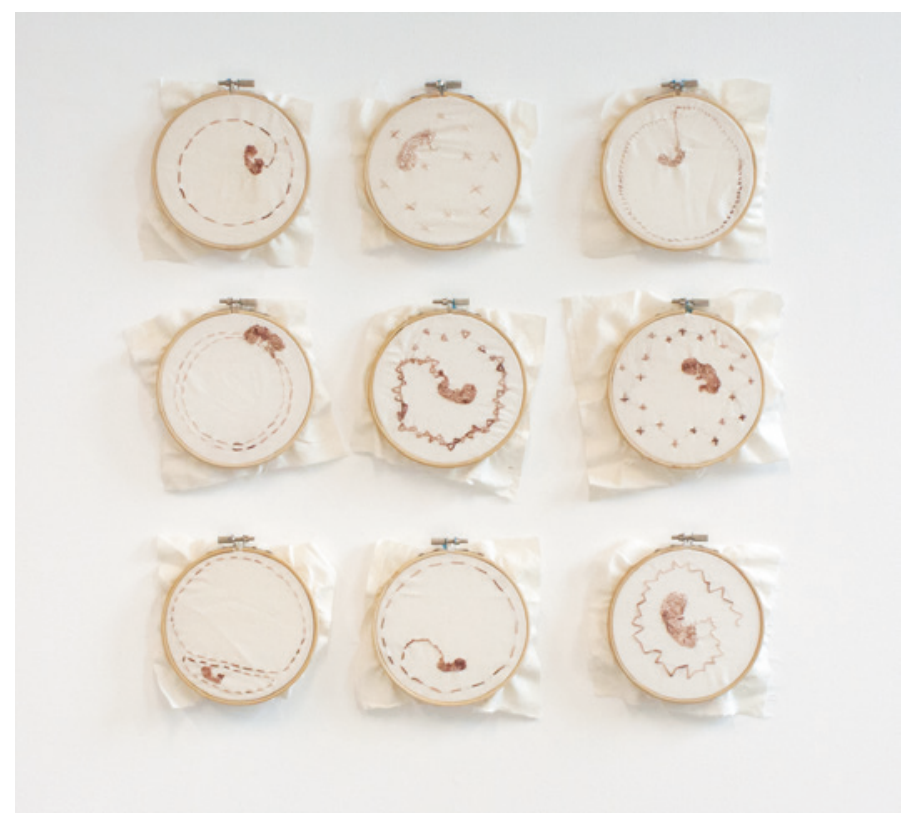

Fig. 58.3 The Lost Ones. Nichole Speciale (Credit: Nichole Speciale 2014)

\section{ARTist's StATEMENT}

Nichole Speciale

The Lost Ones is a group of nine small hoops embroidered with white embroidery thread that has been dyed with menstrual blood. The project seeks to bring attention to both the gendered practice of embroidery and the shaming of the female body. Thread has for many decades been associated with feminine home craft and disregarded as a legitimate art-making medium. In its simplest interpretation, thread is a continuous line. Thread, like the womb, is absorptive. It reflects its environment; it creates new forms from its own tissue. The Lost Ones connects the womb to this gendered material, allowing the thread to act as a conduit for the womb's unused material. On a more social level, the project works to expose the artist's own female body. It reveals an otherwise obscured material that is lessened to the status of excrement, even though it is a material responsible for the creation of life. The depicted fetus shapes serve as reminders of the potential held in the menses (Fig. 58.3). 
Fig. 58.4 Threaded

Together. Johanna

Falzone. Thread, toilet.

Completed in 2013.

Originally installed at the Howard Johnson Motel in St. Augustine, FL (Credit: Johanna

Falzone 2013)

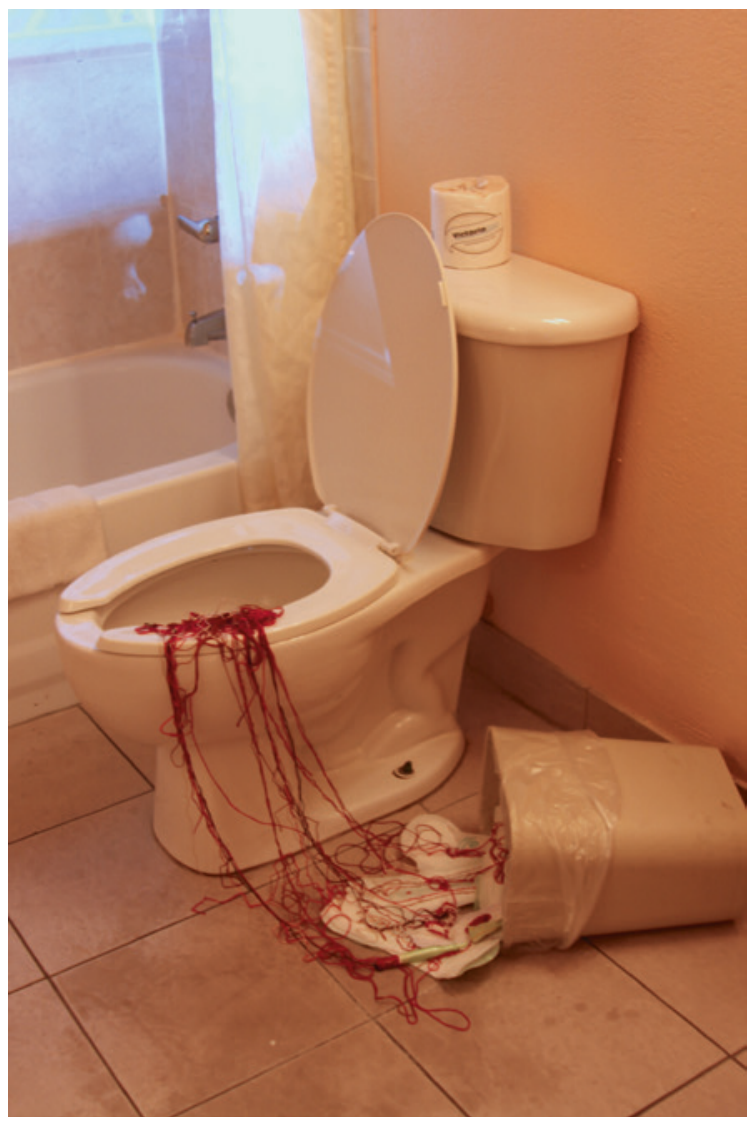

\section{ArtisT's STATEMENT}

\section{Johanna Falzone}

Threaded Together is a site-specific installation work originally on view at a Howard Johnson Motel. The work symbolizes a common thread women have through menstruation. Each pad and tampon is stitched to show how different women may feel about this cycle. Images range from love and reproduction to squiggle blobs, each representing these impressions of what menstruation symbolizes. The installation is placed with a toilet because this is where women change tampons and pads. The toilet is also where fortunate or unfortunate reproductive events, such as miscarriage or using a pregnancy test, may take place. Pregnancy and miscarriage can be both positive and negative outcomes for a woman. No matter how a woman feels about reproduction, this is a cycle women have in common. Menstruation is why women must empathize and celebrate with one another; despite what one's personal beliefs may be, we must respect each woman's choice (Figs. 58.4 and 58.5). 


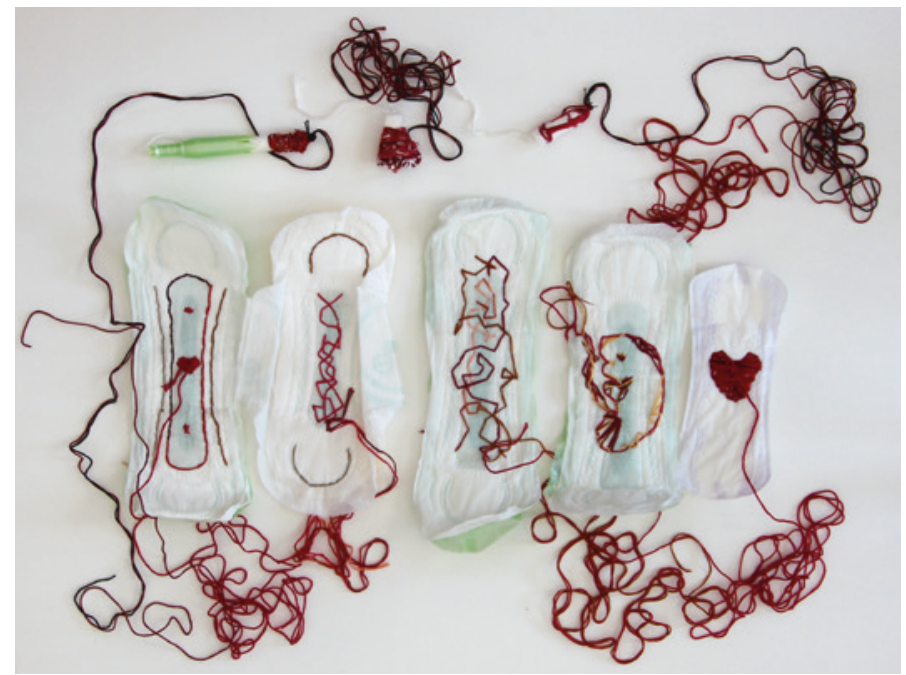

Fig. 58.5 Threaded Together. Johanna Falzone. Thread, tampons, maxi-pads. Completed in 2013. Originally installed at the Howard Johnson Motel in St. Augustine, FL (Credit: Johanna Falzone 2013)

\section{Artist's Statement}

Phoebe Man

In the southern part of China, there is a custom of eating red eggs to celebrate a baby's birth. I combined the red eggs with sanitary napkins to stress the relationship between menstruation and women's reproductive abilities. Arranging these two materials into blossoming flowers shows my positive attitude toward the naturalness of these bodily functions.

The mirror invites the audience to come closer, in order to be with the works and celebrate the bodily functions together. However, in my own experience, when viewers came closer to my work and realized what the materials were, their facial expressions changed greatly. Some even said, "disgusting!" Why did people's attitudes toward the work change so fast?

The monthly period is still a stigma in Chinese society. It is regarded as unlucky and dirty. Why? This is something I want to question through my work.

The work My Mirror is inspired by my anxiety around periods when I was a student. I wanted to enjoy sexual pleasure but did not want to get married and have babies. It was a nightmare when my period came late. These experiences made me want to raise the issue and generate more discussion (Fig. 58.6 and 58.7). 
Fig. 58.6 My Mirror by Phoebe Chin Ying Man. Sanitary napkins, egg shells, and a mirror, $55 \mathrm{~cm} \times 55 \mathrm{~cm} \times 4 \mathrm{~cm}$ (Credit: Phoebe Chin Ying Man 2014)
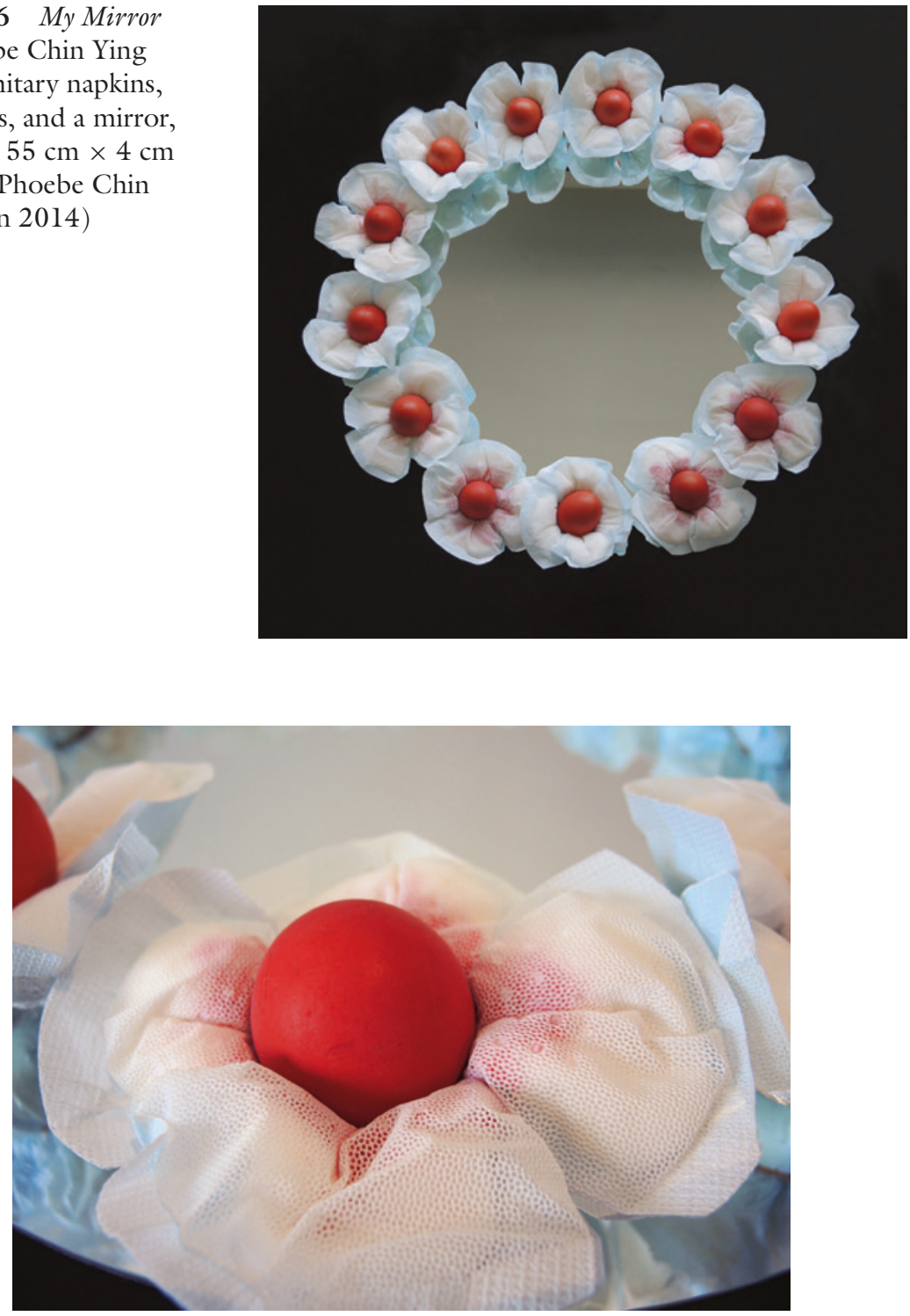

Fig. 58.7 My Mirror (detail) by Phoebe Chin Ying Man. Sanitary napkins, egg shells, and a mirror, $55 \mathrm{~cm} \times 55 \mathrm{~cm} \times 4 \mathrm{~cm}$ (Credit: Phoebe Chin Ying Man 2014) 


\section{Artist's Statement \\ Ingrid Goldbloom Bloch}

Stop the Flow of Violence. PERIOD. is part of a series that transforms recycled and upcycled materials into something entirely different from their intended purpose with the goal of stimulating conversations around polarizing topics. Stop the Flow of Violence. PERIOD. speaks for itself. Through a play on words and the use of a gun made out of surprisingly unconventional materials, I hope to draw viewers into conversations around the politics of gun control/violence and the social taboos surrounding menstruation.

I strive to produce art that is both humorous and surprising. I find beauty in common objects, roadside debris, and cast-offs and hope others will too, as they stop and examine how something was made and transformed into something unexpected (Fig. 58.8).

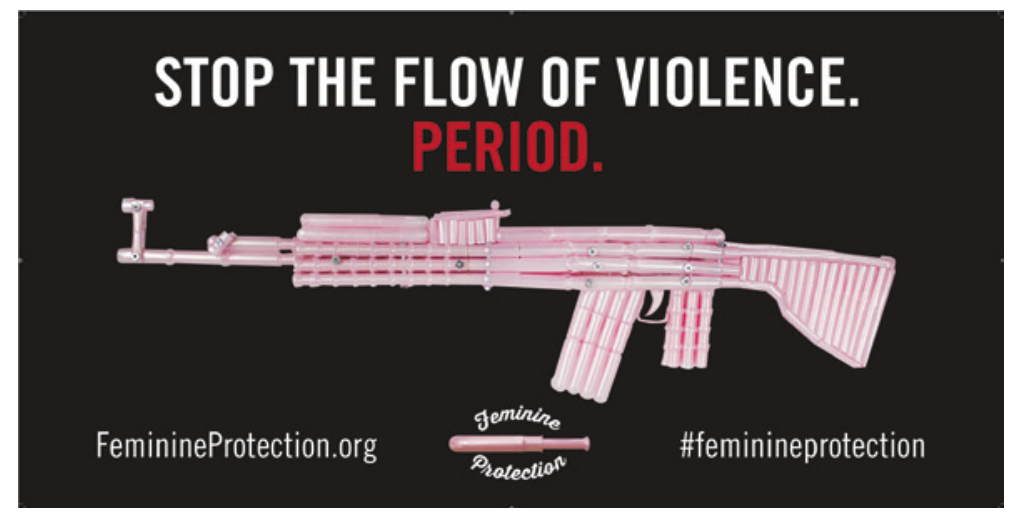

Fig. 58.8 Stop the Flow of Violence. Period. From Feminine Protection? series. Ingrid Goldbloom Bloch. Materials: Plastic tampon applicators, woven together in the shape of an AK-47 (Credit: Ingrid Goldbloom Bloch 2015. Photography: Deb Dutcher. Graphic Design: Cheryl Robock) 
Open Access This chapter is licensed under the terms of the Creative Commons Attribution 4.0 International License (http://creativecommons.org/licenses/ by/4.0/), which permits use, sharing, adaptation, distribution and reproduction in any medium or format, as long as you give appropriate credit to the original author(s) and the source, provide a link to the Creative Commons license and indicate if changes were made.

The images or other third party material in this chapter are included in the chapter's Creative Commons license, unless indicated otherwise in a credit line to the material. If material is not included in the chapter's Creative Commons license and your intended use is not permitted by statutory regulation or exceeds the permitted use, you will need to obtain permission directly from the copyright holder. 